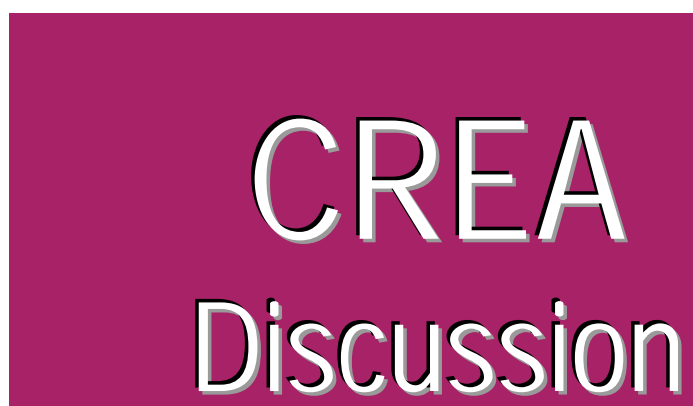
Paper 2016-03

Center for Research in Economics and Management University of Luxembourg

\title{
Population Aging and Inventive Activity
}

available online : http://wwwfr.uni.lu/recherche/fdef/crea/publications2/discussion_papers

Andreas Irmen, CREA, Université du Luxembourg Anastasia Litina, CREA, Université du Luxembourg

March, 2016

For editorial correspondence, please contact: crea@uni.lu

University of Luxembourg Faculty of Law, Economics and Finance $162 \mathrm{~A}$, avenue de la Faïencerie L-1511 Luxembourg 


\title{
Population Aging and Inventive Activity
}

\author{
Andreas Irmen \\ CREA, University of Luxembourg and CESifo, Munich* \\ Anastasia Litina \\ CREA, University of Luxembourg ${ }^{\dagger}$
}

March 18, 2016

\begin{abstract}
This research empirically establishes and theoretically motivates the hypothesis that population aging has a hump-shaped effect on inventive activity. We estimate this hump-shaped relationship in a panel of 33 OECD countries over the period 1960-2012. The increasing part of the hump captures the awareness that population aging requires inventive activity to guarantee current and future standards of living. The decreasing part reflects the tendency of aging societies to lose dynamism and the willingness to take risks. Policy-wise our analysis suggests that raising the awareness of individuals about the consequences of population aging may facilitate the adoption of strategies and policies encouraging inventive activity and economic growth.
\end{abstract}

Keywords: Population Aging, Inventive Activity, Panel Estimation

JEL Classification Numbers: J11, O31, O50, O57

${ }^{*}$ CREA, University of Luxembourg, Faculty of Law, Economics and Finance, 162a, Avenue de la Faïencerie, L - 1511 Luxembourg (e-mail: airmen@uni.lu)

${ }^{\dagger}$ Corresponding Author: CREA, University of Luxembourg, Faculty of Law, Economics and Finance, 162a, Avenue de la Faïencerie, L - 1511 Luxembourg (e-mail: anastasia.litina@uni.lu).

Both authors gratefully acknowledge financial support from the University of Luxembourg under the program "Agecon C - Population Aging: An Exploration of its Effect on Economic Performance and Culture." We would like to thank Antonio Cosma, Katrin Hussinger, Stelios Michalopoulos, Amer Tabaković, Gautam Tripathi, David Weil as well as audiences at the CREA seminar series (University of Luxembourg), at the SEMILUX seminar series, at the CESifo summer workshop on "Demographic Change \& Long-Run Development", at the InGRID summer-school on "Advanced Poverty Research: Poverty and Material Deprivation Dynamics", and at the AMEF conference (University of Ioannina) for useful comments and suggestions. 


\section{Introduction}

What is the relationship between population aging and the propensity to engage in inventive activity? The answer to this question matters for at least two reasons. The first is related to economic growth. It is widely recognized that population aging poses serious challenges for many important fields of economic policy including health care, pensions or public debt (see, e. g., Rechel et al. (2009) or Börsch-Supan (2012)). Economic growth is often seen as a means to solve, or at least to alleviate these problems. Since innovation and technical change are the main drivers of economic growth it is important to know how inventive activities adjust in aging societies. The second reason is cultural. It concerns the hypothesis that old societies tend to lose dynamism, are less forward-looking and more reluctant to accept change. The French demographer, anthropologist and historian Alfred Sauvy (Sauvy (1948), p.188) put this succinctly:

"In countries suffering from ageing, the spirit of enterprise, and hence the willingness to take risks without which capitalism cannot function, gradually atrophies and is replaced by a new feeling: The desire for security."

If Sauvy's conjecture is true then population aging may lead societies into a state of stagnation with little inventive activity. Yet, is this dismal prediction borne out in the data?

The present paper argues that the relationship between population aging and inventive activity is indeed more intricate. For a panel comprising 33 OECD countries over the period 1960-2012 we empirically establish that the effect of population aging on inventive activity is hump-shaped. Our proxy for population aging is a country's old-age dependency ratio, OADR..$^{1}$ We use the number of patent applications per 1000 residents to measure a country's propensity to engage in inventive activity. For the whole panel the estimated peak of the hump occurs at an OADR between 24 and 27, roughly the OADR of Japan for the period 1999-2003 and of Germany for the period 2001-2004. In countries to the left of this critical level the propensity to engage in inventive activity increases, ceteris paribus, with population aging. The opposite holds for countries to the right. ${ }^{2}$

Where does the hump come from? Our interpretation of this finding assumes two simultaneous relationships between inventive activity and population aging (see Figure 1 for an illustration). ${ }^{3}$ The first is increasing and dominates the overall relationship to the left of

\footnotetext{
${ }^{1}$ The OADR is the ratio of the economically dependent old (people older than 64) to the working population aged 15-64. Throughout, this ratio is stated as the number of dependent old per 100 members of the workingage population. The source of our data is the World Bank Indicators.

${ }^{2}$ As shown in Figure 4, for some countries such as Japan or Germany the country-specific, unconditional relationship between the OADR and patent applications per 1000 residents is also hump-shaped.

${ }^{3}$ Here $\Omega$ and $P$ denote the OADR and patents per 100,000 inhabitants, respectively. The first, increasing relationship is $P=f(\Omega)$ where $f: \mathbb{R}_{++} \rightarrow \mathbb{R}_{++}$with $f^{\prime}(\Omega)>0>f^{\prime \prime}(\Omega)$. The second, decreasing relationship is $P=g(\Omega)$ where $g: \mathbb{R}_{++} \rightarrow \mathbb{R}_{++}$with $g^{\prime}(\Omega)<0$ and $g^{\prime \prime}(\Omega)<0$. Then, the sum of these two relationships
} 


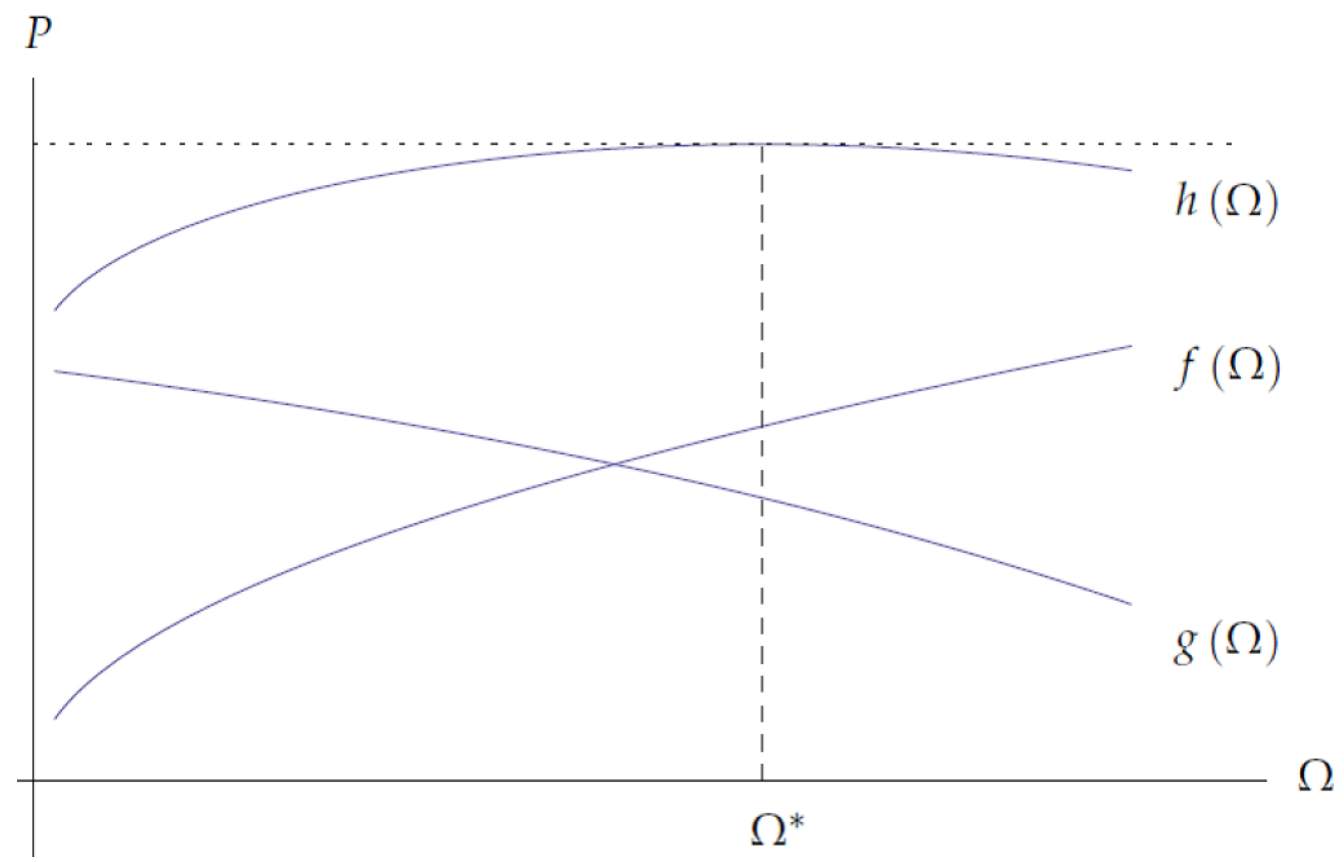

FIGURE 1: Inventive activity as a concave, hump-shaped function of population aging. Here, $\Omega$ denotes the OADR, whereas $P$ represents patents per capita.

the hump, the second is decreasing and dominates to its right. The increasing relationship may capture the spirit of the saying "necessity is the mother of invention." Inventive activity is necessary in aging populations to raise the productivity of the working young. This guarantees a decent standard of living for the economically dependent old while keeping the burden of the supporting working young at an acceptable level. Therefore, we would expect that aging societies implement institutions and policies that foster inventive activity. The decreasing relationship captures Sauvy's conjecture. ${ }^{4}$ Our empirical strategy identifies the sum of these two relationships as a strictly concave, hump-shaped function with a unique interior maximum. ${ }^{5}$

What could policy makers learn from our empirical findings? Clearly, some received policy responses such as encouraging immigration, raising workers' education, or shifting the retirement age are not related to the scope of our inquiry. However, our analysis suggests that a policy of raising the individual awareness about the consequences of population aging is called is $h(\Omega)=f(\Omega)+g(\Omega)$ where $h: \mathbb{R}_{++} \rightarrow \mathbb{R}_{++}$and $h^{\prime \prime}(\Omega)<0$. The critical OADR, $\Omega^{*}$, satisfies $h^{\prime}\left(\Omega^{*}\right)=$ $f^{\prime}\left(\Omega^{*}\right)+g^{\prime}\left(\Omega^{*}\right)=0$. If $f$ and $g$ are such that $\lim _{\Omega \rightarrow 0} h^{\prime}(\Omega)>0$ and $\lim _{\Omega \rightarrow \infty} h^{\prime}(\Omega)<0$ then a unique $\Omega^{*} \in(0, \infty)$ exists which gives a global maximum of $h$.

${ }^{4}$ The literature on the consequences of population aging for economic growth in dynamic economies with probabilistic voting also suggests a decreasing relationship (see, e.g., Kuehnel (2011) or Gonzalez-Eiras and Niepelt (2012)). Here, population aging implies that the median voter gets older. Then, the political-economic equilibrium shifts in favor of the old implying less inventive activity and slower economic growth. However, these models feature no counterpart to the necessity-is-the-mother-of-invention motive.

${ }^{5}$ In a companion paper we establish empirically that population aging also has a hump-shaped effect on individual attitudes towards new ideas and innovation (Irmen and Litina, 2016). 


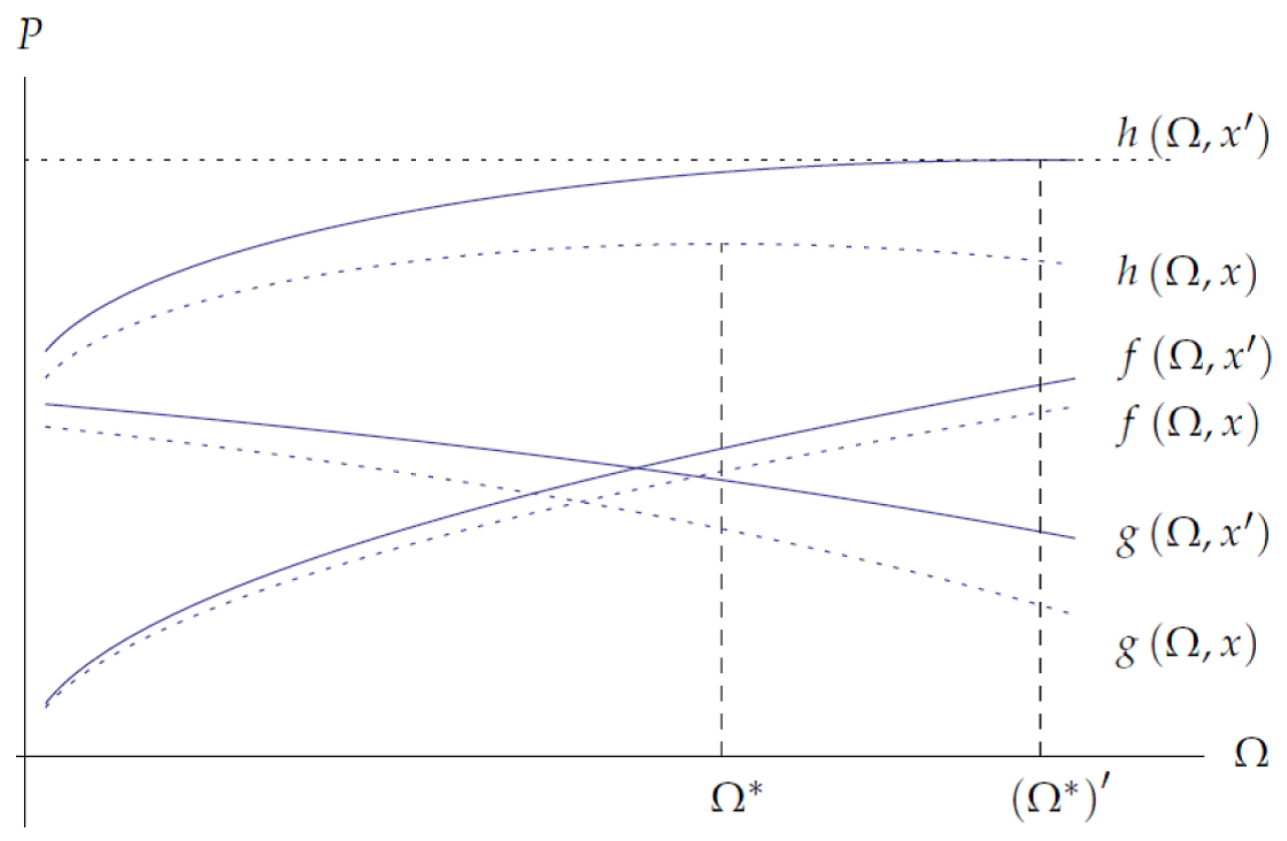

FIGURE 2: A policy of raising awareness about the costs and benefits of population aging may shift the hump to the right.

for. Indeed, informing individuals about the costs and benefits of population aging is likely to change their attitudes towards inventive activity. As a consequence, both relationships shown in Figure 1 should move upwards. Hence, for all levels of population aging the propensity to engage in inventive activity will increase. Under mild conditions this will even lead to a rightward shift of the hump. This is shown in Figure 2. ${ }^{6}$ Thus, raising awareness may place aging countries from the right to the left of the hump. This is the case for all countries with an initial OADR, $\Omega \in\left[\Omega^{*},\left(\Omega^{*}\right)^{\prime}\right]$. Hence, such a policy may facilitate the adoption of strategies encouraging inventive activity and thus economic growth in an attempt to alleviate the adverse consequences of population aging.

We derive our empirical results estimating a panel with country and time fixed effects to capture a large number of time and country-specific unobservables. Moreover, we include

\footnotetext{
${ }^{6}$ Figure 2 extends the setup of Figure 1 explained in Footnote 3. Now, we write the first and the second relationships respectively as $P=f(\Omega, x)$ where $f: \mathbb{R}_{++}^{2} \rightarrow \mathbb{R}_{++}$and $P=g(\Omega, x)$ where $g: \mathbb{R}_{++}^{2} \rightarrow \mathbb{R}_{++}$. Here, $x>0$ reflects the degree of awareness that shifts both relationships upwards, i. e., the partial derivatives with respect to $x$ are $f_{x}(\Omega, x)>0$ and $g_{x}(\Omega, x)>0$. In Figure 2 both relationships shift upwards as $x^{\prime}>x$. Moreover, we maintain that $f_{\Omega}(\Omega, x)>0>f_{\Omega \Omega}(\Omega, x)$, and $g_{\Omega}(\Omega, x)<0$, and $g_{\Omega \Omega}(\Omega, x)<0$. Then, $h(\Omega, x)=f(\Omega, x)+g(\Omega, x)$ where $h: \mathbb{R}_{++}^{2} \rightarrow \mathbb{R}_{++}, h_{\Omega \Omega}(\Omega, x)<0$ and $h_{x}(\Omega, x)>0$. The critical OADR satisfies $h_{\Omega}\left(\Omega^{*}, x\right)=f_{\Omega}\left(\Omega^{*}, x\right)+g_{\Omega}\left(\Omega^{*}, x\right)=0$.

Now, assume that more awareness - a greater $x$ - also increases the slopes $f_{\Omega}$ and $g_{\Omega}$ so that $f_{\Omega x}(\Omega, x)>0$ and $g_{\Omega x}(\Omega, x)>0$. Then, the implicit function theorem delivers

$$
\frac{d \Omega^{*}}{d x}=-\frac{f_{\Omega x}\left(\Omega^{*}, x\right)+g_{\Omega x}\left(\Omega^{*}, x\right)}{h_{\Omega \Omega}\left(\Omega^{*}, x\right)}>0 .
$$

Hence, for a greater level of awareness the global maximum of $h$ occurs at a greater OADR.
} 
a wide range of aggregate level controls including per-capita income, life expectancy, fertility and mortality, institutions, urbanization, aggregate national expenditure (including public spending on education and health), and trade flows. To establish a causal effect of population aging on inventive activity we conduct an IV estimation as well a number of robustness checks testing the different assumptions of our model and accounting for potential confounders of inventive activity. The particularities of each country as captured by the country fixed effects can account for the differential patterns that appear in Figure 4 showing the country-specific, unconditional correlations between patents and the OADR.

Our paper is closely related to the recent empirical literature on the consequences of demographic change and population aging for economic performance (see, Weil (1997) or Bloom and Sousa-Poza (2013) for selective surveys). ${ }^{7}$ For instance, Kogel (2005) argues that a higher youth dependency ratio reduces 'residual', i. e., total factor productivity growth. Gehringer and Prettner (2014) find empirical evidence for a positive correlation between longevity and total factor productivity growth in a panel of 22 OECD countries and a time span from 1960 to 2011. The focus of Feyrer (2007) is on the relationship between workforce demographics and aggregate productivity. According to this author changes in the age structure of the workforce are significantly correlated with changes in aggregate productivity. Poterba (2014) explores the effect of population aging on a wider range of issues including life-cycle planning and retirement. He also argues that an aging population may be associated with a declining rate of innovation.

Another strand of this literature explores the aging-invention nexus focusing on the realm of research (see, e. g., Jones et al. (2014) for a recent survey). Jones (2010) establishes that the age at which noted innovations are produced has increased by approximately 6 years over the 20th century. Packalen and Bhattacharya (2015) find that younger researchers are more likely to build their work on more recently developed ideas.

To the best of our knowledge the present paper is the first that explores the direct link between population aging and inventive activity at the macroeconomic level across countries and time. Moreover, unlike the above-mentioned literature that predicts linear effects we uncover a non-linear, hump-shaped effect of population aging on inventive activity. In other words, the direction of the effect of population aging hinges on its level.

The structure of the present paper is the following. Section 2 describes the empirical strategy and the data used in our paper. Section 3 presents the empirical results for our main research question. Section 4 conducts robustness tests. Section 5 discusses several issues of interest related to our findings whereas Section 6 concludes. The definitions and the sources of the variables used in our analysis are provided in an Appendix.

\footnotetext{
${ }^{7}$ Recent theoretical contributions studying the effect of population aging and economic growth include Irmen (2013) and Prettner (2013).
} 


\section{Data and Empirical Strategy}

This section serves two purposes. First, we describe our data in Section 2.1. Second, we explain our empirical strategy in Section 2.2.

\subsection{The Data}

We study the effect of population aging on inventive activity in an unbalanced panel data set of 33 OECD countries including Australia, Austria, Belgium, Canada, Chile, Czech Republic, Denmark, Estonia, Finland, France, Germany, Greece, Hungary, Ireland, Israel, Italy, Japan, South Korea, Luxembourg, Mexico, the Netherlands, New Zealand, Norway, Poland, Portugal, Slovakia, Slovenia, Spain, Sweden, Switzerland, Turkey, United Kingdom and the United States. For these countries the full set of controls used in the baseline model is available. This is not the case for Iceland which is therefore excluded. We consider annual data for the period 1963-2010. ${ }^{8}$ We consider the included OECD countries as a representative set of the world's industrialized countries that already face the threat of an aging population. ${ }^{9}$

Our proxy for inventive activity is the number of patent applications filed per 1000 inhabitants. The data is available from the World Development Indicators (WDI), and the original source is the World Intellectual Property Organization (WIPO). We choose patent applications as opposed to actual patents to avoid concerns associated with the system of patent granting. As such, patent applications appear to be a better proxy for the inventive activity of a given year. In Section 4, we use the number of researchers in the Research and Development sector per million people as an alternative proxy for inventive activity. Here, the source is again the World Development Indicators.

Our dependent variable is the old-age dependency ratio (OADR) which we interpret as the proxy for population aging. The OADR states the number of people above the age of 65 -the old- per 100 people of the working population aged 15-64. In Section 4 we use the number of old people per 100 members of the total population as a measure of population aging and we show that our main results still hold. Moreover, we conduct placebo tests with the young age dependency ratio, i.e., the ratio of young people (below 15) per 100 members of the working age population.

Our analysis controls for a wide range of confounders, also available from the WDI. They include income per capita, life expectancy, fertility and mortality rates, urbanization,

\footnotetext{
${ }^{8}$ Our panel is unbalanced. However, for country level data this is not due to attrition and, therefore, of little concern. The sample of already developed OECD countries mitigates this concern even further. Moreover, we replicated our analysis taking 3-year and 5-year aggregates of all included variables. This reduces the role of missing observations and absorbs the potential effect of cyclical fluctuations. We show in Section 4 that with 3 -year and 5-year aggregates our main result remains valid.

${ }^{9}$ In Section 4 we establish that our results hold for alternative samples as well as for the sample of 123 countries for which the full set of baseline controls is available.
} 
institutional quality, gross national expenditure, GNE, and trade flows as a percentage of GDP. All of these variables qualify as plausible determinants of inventive activity. Section 4 takes additional controls into account that are only available for shorter time periods or for fewer countries. They include population density, secondary enrollment rates, the ICRG measure of corruption, unemployment rates, and immigration stocks. We do not employ all these controls in the baseline model to keep the sample as large as possible.

\section{[TABLE 1 ABOUT HERE]}

\section{[TABLE 2 ABOUT HERE]}

Tables 1 and 2 provide the summary statistics for the sample of 33 countries over the period 1960-2012. The panel has 1225 observations. The sample features primarily developed countries with a mean annual per-capita income of 23,706 in constant $\$ 2005$. Most of these countries were democratic throughout most of the years with an average institutional quality score of approximately 8.5 on a scale from -10 to 10 . The average life expectancy at birth is 75 years, the average total fertility rate is 2 births per woman. Crucially, in this set of countries the OADR varies from 6 (for Turkey in the 70's) to 39 (for Japan during the last decade). The number of patent applications per 1000 inhabitants also varies considerably from 0.001 (again for Turkey in the 70's) to 3.028 for Japan (during the last decade).

\section{[FIGURE 4 ABOUT HERE]}

Figure 4 illustrates the unconditional correlations between the number of patent applications per 1000 inhabitants ("Patents") and the OADR in a scatter plot for each country in the sample. Several non-linear patterns emerge. For instance, humps occur for Finland (FIN) and Japan (JPN). Hump approximations may also be traced for Chile (CHL), Germany (DEU), Great Britain (GBR) or Ireland (IRL). The remaining countries exhibit different patterns. To account for these disparities our empirical analysis adopts a non-linear specification. In addition, we account for several explanatory variables and include country fixed effects to exploit within country variation.

\section{$2.2 \quad$ Empirical Strategy}

This section introduces our baseline model as well as our IV estimation.

\subsubsection{The Baseline Model}

We estimate the baseline model described by 


$$
P_{i t}=\alpha_{0}+\alpha_{1} \Omega_{i t}+\alpha_{2} \Omega_{i t}^{2}+\alpha_{3} \mathbf{X}_{i t}+\alpha_{4} \mathbf{I}_{i}+\alpha_{5} \mathbf{T}_{t}+\varepsilon_{i t}
$$

Here, $P_{i t}$ is the number of patent applications per 1000 inhabitants filed by residents of country $i$ at time $t$. The OADR is denoted by $\Omega_{i t}$, whereas $\Omega_{i t}^{2}$ is its squared value. The presence of the quadratic term allows for the identification of a non-linear effect of population aging on inventive activity. ${ }^{10}$ The vector of confounders, $\mathbf{X}_{i t}$, includes a large number of time varying controls that may have an effect on inventive activity. It includes income per capita, life expectancy, fertility and mortality rates, urbanization rates, institutional quality, gross national expenditure, and international trade flows, both as a percentage of GDP. The vector of country fixed effects, $\mathbf{I}_{i}$, captures unobserved heterogeneity at the country level, at least for time invariant characteristics such as geography or climate. The vector of year fixed effects, $\mathbf{T}_{t}$, captures time specific shocks. Finally, $\varepsilon_{i t}$ is the country and time specific error term.

\subsubsection{Estimation}

Reverse causality and omitted variable bias may conflate our estimations even though we control for many sources of unobserved heterogeneity via time-varying controls, country and time fixed effects. ${ }^{11}$ To further address potential endogeneity concerns we adopt an IV estimation of our baseline model. ${ }^{12}$

An omitted variable bias may matter if there is some unobserved or omitted variable that simultaneously affects population aging and inventive activity. We use rates of immunization against measles as an instrument. Measles is an infection of the respiratory system, immune system and skin caused by a virus (Griffin, 2002). It is a particularly contagious disease that affects primarily children but anyone may be contaminated who has not been immunized against the disease. Whereas the fight against the disease is quite advanced, it may nevertheless create complications and lead to death. Crucially, the symptoms of the disease become more severe with age. For 2011, the World Health Organization estimates that approximately 158,000 people died worldwide of measles, whereas in 1990 this number was as high as 630,000 . In developed countries $1 \%$ of people infected with measles may die from complications whereas in developing countries this rate is as high as $10 \% .{ }^{13}$ Treatments against measles are available, however, the best protection is immunization.

\footnotetext{
${ }^{10}$ In Section 4 we investigate the non-linear specification further. In particular, we show that neither a purely linear specification nor an additional cubic term is supported by the data.

${ }^{11}$ In addition, in Section 4 we show that our results also hold in a first-differences model and in a dynamic panel analysis.

${ }^{12}$ In Section 4 we further discuss both sources of endogeneity. Specifically, we use the lagged values of population aging to address reverse causality. Moreover, we replicate the analysis of our baseline model using patent applications in specific sectors as the dependent variable.

${ }^{13}$ WHO Factsheet: http://www.who.int/mediacentre/factsheets/fs286/en/ (accessed on March 15, 2016 ).
} 
We use a child immunization measure as an instrument. More precisely, our instrument is the fraction of children aged 12-23 months who received a vaccination before their 12th month. A child is considered adequately immunized against measles after receiving one dose of vaccine. The data is part of the World Development Indicators. A mechanism through which our instrument affects the endogenous regressor, OADR, operates via positive spill-overs of immunization to the health status of the population as a whole. If this status improves then the fraction of the old in the population, who are on average more vulnerable, tends to increase. ${ }^{14}$ Whereas vaccination is the best protection against the disease, not all OECD countries impose mandatory vaccination. Our IV strategy exploits this variation in vaccination rates. ${ }^{15}$

Our identifying assumption is that country specific levels of immunization against measles are not correlated with patents filed each year by residents of the respective country. This is quite plausible. Since the 1960's the quality of the vaccine against measles is so advanced that the total population may be protected provided that all individuals are vaccinated. Therefore, it is very unlikely that recent inventive efforts are still targeted towards improving the vaccine against measles. This argument also rules out a causality running from patents to vaccination rates.

Potentially, measles may affect inventive activity via other, indirect channels. We introduce a number of time varying controls to address this issue. In particular, we use life expectancy and mortality rates to control for the potential effect that immunization against measles could have on the health capital of individuals which, in turn, could improve their capacity to innovate. Moreover, we control for gross national expenditure which includes spending on education and health. Whereas the former captures a potential effect of vaccination on the incentives to build human capital, the latter captures changes in the allocation of funds to health issues. It is hard to argue that immunization against measles could be systematically correlated with any of the above factors. Nevertheless, controlling for them further supports the claim that our IV strategy satisfies the exclusion restriction.

Hence, the fraction of children immunized against measles is a valid instrument for the OADR. Since the second stage is quadratic in the endogenous regressor, it is necessary for the 2SLS regression to instrument for both the OADR and its squared term. Then, the system of equations is exactly identified. We apply the two step procedure suggested by Wooldridge

\footnotetext{
${ }^{14}$ One could think of weakening effects. However the unconditional correlation between our instrument and the endogenous regressor is positive $(\simeq 0.18)$. Moreover the conditional correlation is also positive and highly significant (see Table 4 below).

${ }^{15}$ Data on recent outbreaks of measles are quite revealing as to the negative externality of low rates of immunization. In 2007, an outbreak of measles in Japan prompted a closing of universities and other public institutions in an attempt to contain the spread of the disease. In 2008, measle epidemics were reported in Austria, Italy, Switzerland and the UK with more than 1200 reported cases in the latter country. Similarly in 2009, two schools in Wales were closed after an outbreak of the disease. France had 17,000 reported cases of measles between 2008 and 2011 with 8 fatalities. In the US, more than 500 people died of measles every year during the last decade.
} 
(2010), Section 9.5. First, the OADR is regressed on the fraction of children immunized against measles using all second-stage controls. This delivers predicted values of the OADR. The predicted OADR from the first stage is then squared. Finally, this value is used as an excluded instrument in the second stage along with the instrument "rates of immunization against measles."

\section{Empirical Findings}

This section develops our findings for the baseline model and for the IV estimation.

\subsection{Findings for the Baseline Model}

Column (1) of Table 3 shows that the estimated value of $\alpha_{1}$ is strictly positive whereas the estimated value of $\alpha_{2}$ is strictly negative. Both estimates are significant at the $1 \%$ level. This specification has year and country fixed effects. Hence, the effect of population aging on inventive activity is hump-shaped. The hump attains a maximum of 4.18 patents per 1000 inhabitants at an OADR of approximately 24.42 .

\section{[TABLE 3 ABOUT HERE]}

The remaining columns gradually introduce our additional time varying controls that are available for the baseline model. ${ }^{16}$ Column (2) introduces a control for income per capita to capture the stage of development of the country. As anticipated, higher levels of income are associated with a higher number of patent applications. Column (3) adds three demographic controls, mortality rates, life expectancy and fertility rates, that may capture a long lasting effect on the incentives of individuals to invest in education and on their ability to invent. Only life expectancy confers a statistically significant effect which comes with a negative coefficient, perhaps reflecting the fact that all countries in the sample are in the post-demographic transition period. Column (4) augments the set of controls with the urbanization rate to capture the effects of clustering around cities and of increasing returns due to agglomeration. Columns (5) and (6) present the results obtained with the inclusion of institutional quality and of gross national expenditure. GNE, i.e., gross national expenditure as a percentage of GDP, includes all types of government final consumption. Hence, this variable implicitly controls for public level investments in health and education infrastructure. ${ }^{17}$ Interestingly, all these

\footnotetext{
${ }^{16}$ Section 4 uses a smaller sample in order to control for an even larger number of time varying controls. As Table 8 illustrates, the results are unaffected by the addition of these controls. The coefficients as well as R-squared remain roughly stable, implying that unobservables do not appear to be of concern.

${ }^{17}$ We use the aggregate measure GNE since this is the only measure available for such a long period. A disaggregation of GNE is possible but data is only available for shorter time periods.
} 


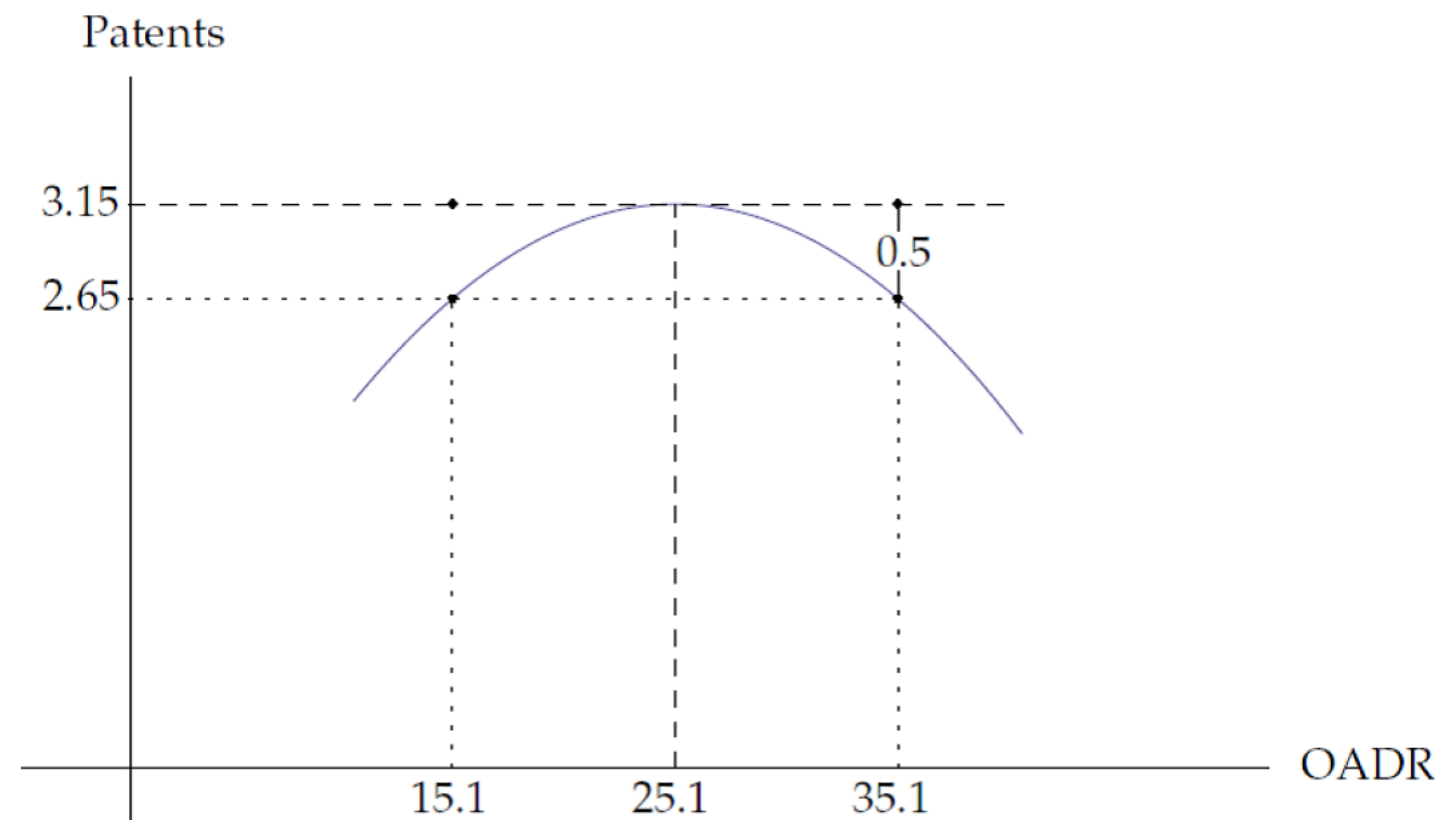

Figure 3: Properties of the hump for the baseline model.

controls are insignificant, perhaps because the suggested channels are already captured by the control "Log Income per Capita."

Finally, Column (7) adds the control "Trade Flows as a \% of GDP." The coefficient is negative and significant implying that the higher the trade volume the lower is the number of patent applications. This result could be related to trade crowding out domestic inventive activity. Henceforth, we shall refer to the specification in Column (7), which includes the full set of controls, as the baseline specification.

Reassuringly, the regressions of Columns (1) to (7) suggest a significant effect of population aging on inventive activity. Moreover, the estimated coefficients for $O A D R$ and for $O A D R^{2}$ remain remarkably stable in all columns. Turning to some orders of magnitude, notice that the hump attains its maximum of 3.15 patents per 1000 inhabitants at an OADR of approximately 25.1. This is illustrated in Figure 3. For countries like Japan or Germany with an OADR in 2010 of about 36 and 32, respectively, further population aging is predicted to have an adverse effect on inventive activity, holding everything else constant. On the contrary, countries like Israel with an OADR of 17 or Canada with an OADR of 20 in 2010 find themselves to the left of the hump's maximum. Therefore, further population aging is predicted to increase inventive activity. At its peak a 10 point change in the OADR (i.e., moving the OADR to 35.1 or to 15.1) is associated with a decrease in the number of patent applications per 1000 inhabitants of 0.5. Roughly, this corresponds to a decline of 16\%. Given that the range of "patents per 1000 inhabitants" in our sample extends from 0 to 3 the order of magnitude of this decline is substantial. 


\subsection{Findings for the IV Estimation}

The findings of our baseline specification suggest that the results are not merely reflecting the possible influence of some unobserved country-specific attributes. The finding that population aging has a significant hump-shaped correlation with inventive activity appears to be quite robust and the coefficients are quite stable across specifications. However, to further mitigate potential endogeneity concerns, this section presents the IV estimation outlined above.

Endogeneity is either due to reverse causality or to unobservables. The reverse causality issue is addressed in Section 4, where lagged values of the old-age dependency ratio replace contemporaneous values. Our IV strategy addresses both types of endogeneity. As described in the previous section, our instrumental variables are the fraction of children aged 1-3 immunized against measles and the predicted value of the OADR.

\section{[TABLE 4 ABOUT HERE]}

The results of our IV estimation are shown in Table 4. We use the same sample of 33 OECD countries as above. Due to limited data on measle immunization rates for earlier periods we restrict attention to the time period 1980-2012.

Column (1) reports the OLS results obtained for the full set of controls used in our baseline specification. Comparing this to Column (7) of Table 3 reveals that the coefficients are somewhat larger for the IV estimation.

Columns (2) and (3) present the results of the first stage regression (reported in the upper part of the table). It suggests that immunization against measles has a positive and statistically significant effect on the old-age dependency ratio for both the linear and the quadratic terms.

Column (4) presents the results of the second stage of the 2SLS procedure. The dependent variable, i.e., the number of patents per 1000 inhabitants, is now regressed on the linear and the quadratic term of the old-age dependency ratio, instrumented by the measles immunization rate and the predicted quadratic term of the OADR. Moreover, the full set of controls of our baseline model is used. Reassuringly, the effect of both the linear and the quadratic coefficients of population aging on patents remains hump-shaped and statistically significant at the $1 \%$ level. Moreover, the weak identification test suggests that we must reject the null hypothesis of weak identification.

The coefficients remain quite stable, potentially reflecting the fact that endogeneity and omitted variables bias is not a major concern in the context of our analysis. Interestingly, the maximum of the hump under the IV estimation is at a level of 3.1 patents per 1000 inhabitants. This is roughly the same value obtained for our baseline regression. However, under the IV estimation this maximum is attained at an OADR of roughly 29 whereas in the baseline regression the corresponding OADR is roughly 25 . The reason is that for the time 
period considered in the IV estimation the mean OADR has increased. Thus, compared to Table 3 population aging is conducive to inventive activity at even higher levels of the OADR.

\section{Robustness}

\subsection{External Validity}

One important question is whether our main result holds only for the sample of OECD countries or whether it is also valid for a wider range of countries. As discussed in Section 2.1, we consider the 33 OECD countries as a natural set of countries where population aging is a plausible concern. Here, we show that our main result is also valid for the complete set of the worlds' countries for which data is available. Moreover it is valid for the subset of countries selected under different assumptions.

\section{[TABLE 5 ABOUT HERE]}

Consider Table 5. Column (1) uses a world sample whereas Column (2) is based on a sample of non-OECD countries. Columns (3) - (5) use samples of countries where life expectancy is higher than 50 years, higher than 60 years, or higher than 70 years, respectively. Columns (6) - (8) is based on samples of countries where, respectively, the birth rate is lower than 4,3 , or 2 children per women. The regressions in all columns feature the full set of controls used in the baseline specification.

Our findings may be interpreted as follows. First, our main result is confirmed in all samples except for the non-OECD countries. This suggests that the result is primarily driven by countries faced with the threat of an aging population. Moreover, our results become increasingly stronger once we move to countries were population aging is an imminent problem since life expectancy is higher and/or fertility is lower. As far as the peak of the hump is concerned the effect of population aging on inventive activity reverses at higher levels of the OADR as we move to older countries. For instance for the whole world the peak occurs at a level of 26.5, whereas for countries with life expectancy higher than 70 years the peak occurs at 30 .

\subsection{Alternative Specifications}

Table 6 shows the results for several alternative specifications. The full set of controls available for the baseline model is always employed.

[TABLE 6 ABOUT HERE] 
Column (1) uses lagged values of the OADR as the main explanatory variable of inventive activity. Our estimates are similar in magnitude and significance to the baseline regression. This finding further mitigates potential concerns about reverse causality.

Column (2) shows the findings of a first-difference model. Our main result remains largely intact with both coefficients reducing somewhat in magnitude.

Column (3) adopts a more demanding specification and estimates a dynamic panel model. We interpret our findings with caution as the dynamic panel format introduces a bias into our model. ${ }^{18}$ Our findings are still significant at the $5 \%$ and $10 \%$ level, whereas the coefficient of lagged patents is highly significant. Hence, introducing some inertia coming from R\&D of the previous period somewhat tends to lower the OADR at which the hump peaks. It is now at a level of 22.6 .

Column (4) adds time trends to capture omitted trends that affect all OECD countries. This also leaves our main result unchanged.

Finally, Columns (5) and (6) shows the results using, respectively, 3-year and 5-year aggregates of all included variables. Our main result is robust to both aggregations. This reduces the role of missing observations and absorbs the potential effect of cyclical fluctuations.

\section{[TABLE 7 ABOUT HERE]}

The specifications of Table 7 further challenge our choice of a quadratic estimation. Recall that the patterns shown in Figure 4 suggest a non-linear effect, yet they do not always hint at a quadratic functional relationship. Column (1) in Table 7 explores the alternative of a linear specification. Clearly, the linear relationship is not supported by the data. Column (2) introduces a cubic specification. All three terms are highly significant. However, the coefficient on the cubic term is equal to 0, thus supporting our choice of a quadratic specification.

\subsection{Additional Controls}

Our baseline specification includes a set of controls that maximizes the number of observations. Additional controls that are only available for a shorter time period or for fewer countries are introduced in Table 8. They include population density, secondary enrollment rates, the ICRG measure of corruption, unemployment rates, and immigration stocks. All these controls could confer an effect on inventive activity. Introducing these controls gradually on top of the controls used for the baseline specification does not alter our main result. The peak of the hump remains roughly at a level of the OADR equal to 25 . Hence, the inclusion of a wide range

\footnotetext{
${ }^{18}$ Whereas the coexistence of country fixed effects and of lagged values of the dependent variable may yield inconsistent estimates, the bias nevertheless gets smaller in magnitude and ultimately becomes negligible as the time dimension reaches infinity (Nickell, 1981). Judson and Owen (1999) suggest that the bias on the lagged dependent variable is around $2-3 \%$ for 20 periods. This number drops to $1-2 \%$ for 30 periods.
} 
of time varying controls along with the fixed effect estimator indicates that unobservables are not driving the results.

[TABLE 8 ABOUT HERE]

\subsection{Cross-Sectional Dependence and Unit Roots}

We conducted Fisher type unit root tests (Choi, 2001) as well as the Peasaran test for crosssectional dependence (Pesaran, 2004). Our findings (not reported but available upon request) do not suggest cross-sectional dependence or the presence of a unit root.

\subsection{Outliers}

In order to account for potential outliers, we conduct a weighted regression test where the most influential points are dropped, and sequentially cases with large absolute residuals are down-weighted. The results (not reported but available upon request) remain qualitatively unaffected.

\section{Discussion}

This section discusses several issues of interest related to our findings.

\subsection{Population Aging and Innovating Sectors}

Is the effect of population aging on inventive activity hump-shaped if we switch from the country level to the level of particular innovating sectors? This section establishes a humpshaped effect for a subset of innovating sectors.

As in our baseline regressions, we analyze a sample of 33 OECD countries. We consider the period 1979-2011 for which the OECD statistics provide data on 12 distinct sectors. Our findings are shown in Table 9.

\section{[TABLE 9 ABOUT HERE]}

The dependent variable is now patent applications in each sector per 10,000 inhabitants. Column (1) illustrates the results for the aggregate number of patents using the full set of controls as in our baseline analysis above. The results are significant at the $5 \%$ level. In Column (2) - (6) of Panel A, the OADR has a significant effect on most of the sectors (with the exception of Biotechnology). In Columns (1) - (6) of Panel B, population aging does not 
confer any significant effect on inventive activity, not even in sectors that one would have anticipated such as the pharmaceutical or the medical sector.

There are at least two reasons why these findings are of interest. First, population aging has no effect on sectors related to improvements in medical technology or in technology that can prolong the life of individuals. This finding further mitigates potential concerns about reverse causality of medical innovations on population aging. Second, the fact that the OADR has an effect on sectors such as nanotechnology, physics or chemistry potentially indicates that population aging has an effect on inventive activity via fostering technical change. The peak of the hump, if it exists, may occur at a wide range of values.

\subsection{Demographic Structure, Pension Scheme, Retirement Age and R\&D}

Consider Table 10 where we use the same set of controls as in the baseline model in all columns. In Column (1) the main explanatory variable for inventive activity is the fraction of the old aged 65 and above to the total population (as opposed to the working age population). According to the summary statistics of the sample this fraction varies from 0.33 to 24.4 . The results remain quite strong and significant at the $5 \%$ level. The peak of the hump occurs at the level of 17.95 old people per 100 members of the total population. Not surprisingly, this number is smaller than the estimated level of the OADR that delivers the peak in our baseline regressions. ${ }^{19}$

\section{[TABLE 10 ABOUT HERE]}

Column (2) conducts a "placebo" test using the youth dependency ratio, i.e., the ratio of the young population below the age of 16 to the working age population aged 15-64. The purpose is to explore whether our main result is truly driven by the presence of the old or whether there is something related to the structure of the population that is being masked by the old-age dependency ratio. Interestingly, we find that none of the two terms comes out as significant. This suggests that our main finding does not operate via the demographic

\footnotetext{
${ }^{19}$ To relate the level of 17.95 to the level of the old-age dependency ratio of 25.1 that delivers the peak in our baseline regression (see Figure 3) note that both numbers are closely related. To see this, denote the fraction of the old in the total population at $t$ by $O T P_{t}$, the total population in working age at $t$ by $L_{t}$, and the total population at $t$ by $N_{t}$. Then, $O T P_{t} \equiv L_{t-1} / N_{t}$. Moreover, with $L_{t+1}$ denoting kids alive at $t$ we have $N_{t} \equiv L_{t-1}+L_{t}+L_{t+1}$. Hence,

$$
O T P_{t}=O A D R_{t} \times \frac{L_{t}}{N_{t}}=O A D R_{t} \times W T P_{t}
$$

where $W T P_{t}$ is the fraction of people in working age in the total population. Then, the peak values of the OTP and the OADR imply a corresponding value $W T P=17.95 / 25.1=0.715$.
} 
structure of the population or via the fraction of the future OADR, i.e., the current young. ${ }^{20}$ On the contrary, it is the presence of the old that triggers our results.

Column (3) explores the role of the pension system. Using several OECD sources we construct a dummy variable that takes on the value of 1 if the pension system is a Pay-AsYou-Go (PAYG) system and a value of 0 in all other cases that include fully-funded, partially funded, book reserved schemes, or any combination of these. The data are constructed using the type of pension scheme in the year 2013. The reason for structuring our variable in such a way is that a PAYG system imposes a direct burden on the young people in working age. Under this system it is reasonable to believe that the problem of aging is perceived by the young in a more transparent way than in alternative pension scheme.

We interact this dummy with the OADR and its squared term. Interestingly, our results indicate that the interaction terms come out as highly significant. Thus suggests that the results are more pronounced in the presence of the PAYG. The peak of the hump now occurs at a level of 27.3 which is similar to the one obtained in the baseline regression.

Column (4) explores whether our main result hinges on the country-specific retirement age of individuals. Our variable "Retirement Age" is constructed using several OECD sources. It takes on the value of 0 if the retirement age is below 63 and the value of 1 otherwise. The data is derived from 2013 OECD reports. We use a dummy variable since there are several exceptions to the general rules defining the retirement age, and moreover, there are differences for men and women. Overall, we aimed at minimizing the level of errors. As shown in Column (4), none of the interaction terms come out as significant. This suggests that the retirement age confers no significant effect on our main result.

Finally, Column (5) addresses potential concerns on the measure of inventive activity employed. For this purpose we use an alternative measure, namely the number of researchers employed in R\&D per one million people. For reasons of data limitations our sample has 32 OECD countries for the period 1997-2010. Reassuringly, our main findings remain highly significant. The implied peak of the hump occurs now at an OADR of roughly 26.2. This result is interpreted not only as a robustness check on the dependent variable, but can also indicate one potential channel via which aging affects inventive activity due to policy considerations. The number of researchers employed in R\&D heavily relies on policy decisions related to the funding of R\&D activities. We thus infer that in the face of aging, policy becomes more R\&D oriented.

\footnotetext{
${ }^{20}$ Using the notation of Footnote 19 the young-age dependency ratio at time $t$ is defined as $Y A D R_{t}=$ $L_{t+1} / L_{t}=1 / O A D R_{t+1}$.
} 


\section{Concluding Remarks}

This paper explores the intricate relationship between population aging and inventive activity. We empirically establish a hump-shaped effect of population aging on inventive activity. We attribute the increasing part of the hump to a rising awareness that the aging of the population necessitates inventive activity to keep the standards of living at current levels for both the economically dependent old and for the supporting working young. We attribute the decreasing part of the hump to Sauvy's conjecture according to which old societies lose the spirit of enterprise and the willingness to take risks. In our panel, the interplay of these two opposing forces gives rise to a hump with an estimated peak at an OADR between 24 and 27.

In a companion paper (Irmen and Litina, 2016), we estimate the effect of population aging on individual attitudes towards new ideas and risk. We find this effect to be hump-shaped, too. Hence, even from this perspective, it is highly questionable that Sauvy's conjecture is valid for all levels of population aging.

Our findings suggest interesting policy implications. Informing citizens about the consequences of population aging may shift the hump. As a consequence, aging societies may develop a more receptive attitude towards inventive activity. This may facilitate the implementation of strategies and policies that foster inventive activity and eventually help alleviate the adverse economic consequences of population aging. 


\section{TABLES AND FIGURES}

The following pages present all tables and figures referred to in the main text. 
TABle 1: Summary Statistics

\begin{tabular}{lccccc}
\hline & Obs & Mean & Std. & Min & Max \\
Patents per 1000 Inh. & 1225 & 0.281 & 0.472 & 0.001 & 3.028 \\
OADR per 100 Inh. & 1225 & 18.685 & 5.770 & 5.951 & 39.043 \\
Income Per Capita & 1225 & $23,706.73$ & $14,396.6$ & 1106.754 & $86,127.24$ \\
Institutional Quality & 1225 & 8.466 & 4.0255 & -9 & 10 \\
Urbanization Rate & 1225 & 1.298 & 1.215 & -2.051 & 7.543 \\
Mortality Rate & 1225 & 125.393 & 48.107 & 54.234 & 354.973 \\
Life Expectancy & 1225 & 74.541 & 5.189 & 47.574 & 83.096 \\
Fertility Rate & 1225 & 2.060 & 0.9384 & 1.076 & 6.777 \\
Trade Flows as \% of GDP & 1225 & 68.031 & 42.568 & 8.333 & 349.849 \\
GNE as \% of GDP & 1225 & 99.572 & 6.337 & 67.113 & 124.5386
\end{tabular}




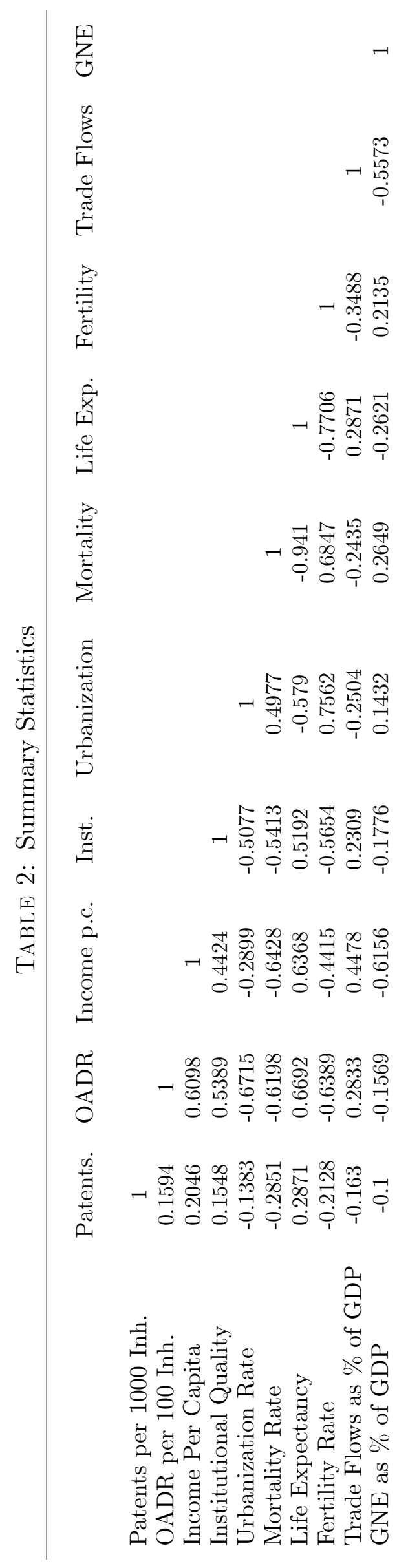



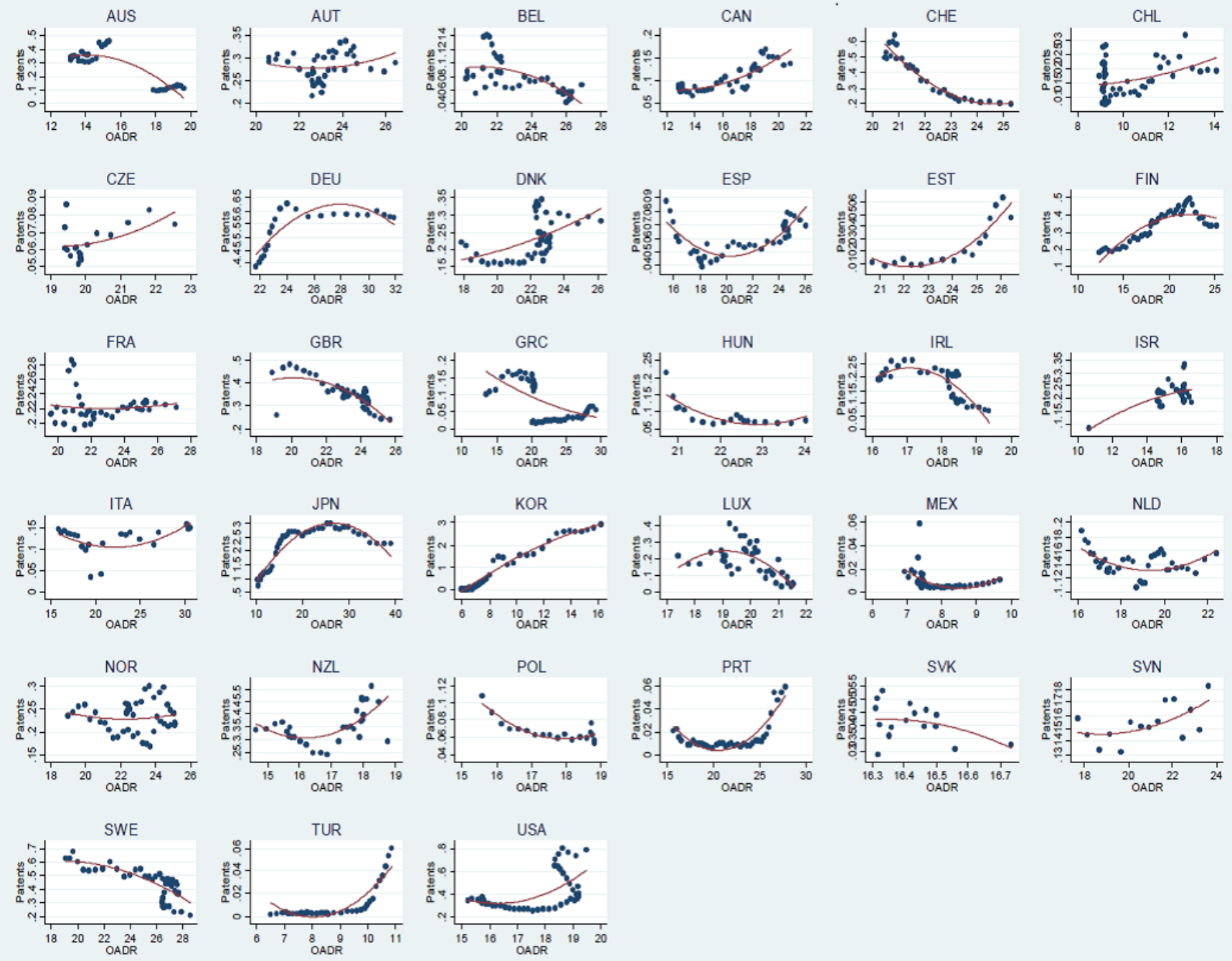

Figure 4: Country-specific, unconditional correlations between Patents and OADR. 


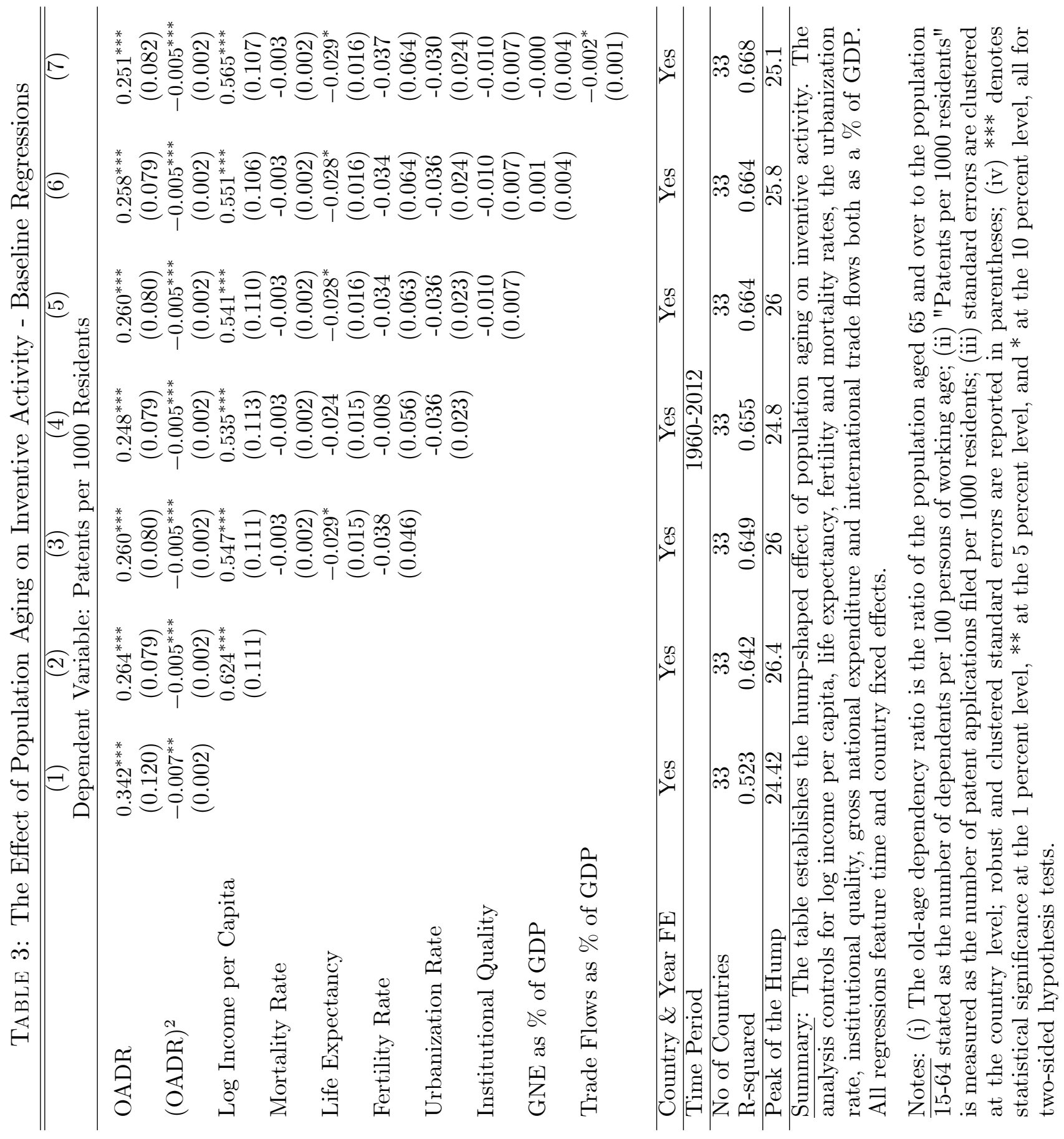




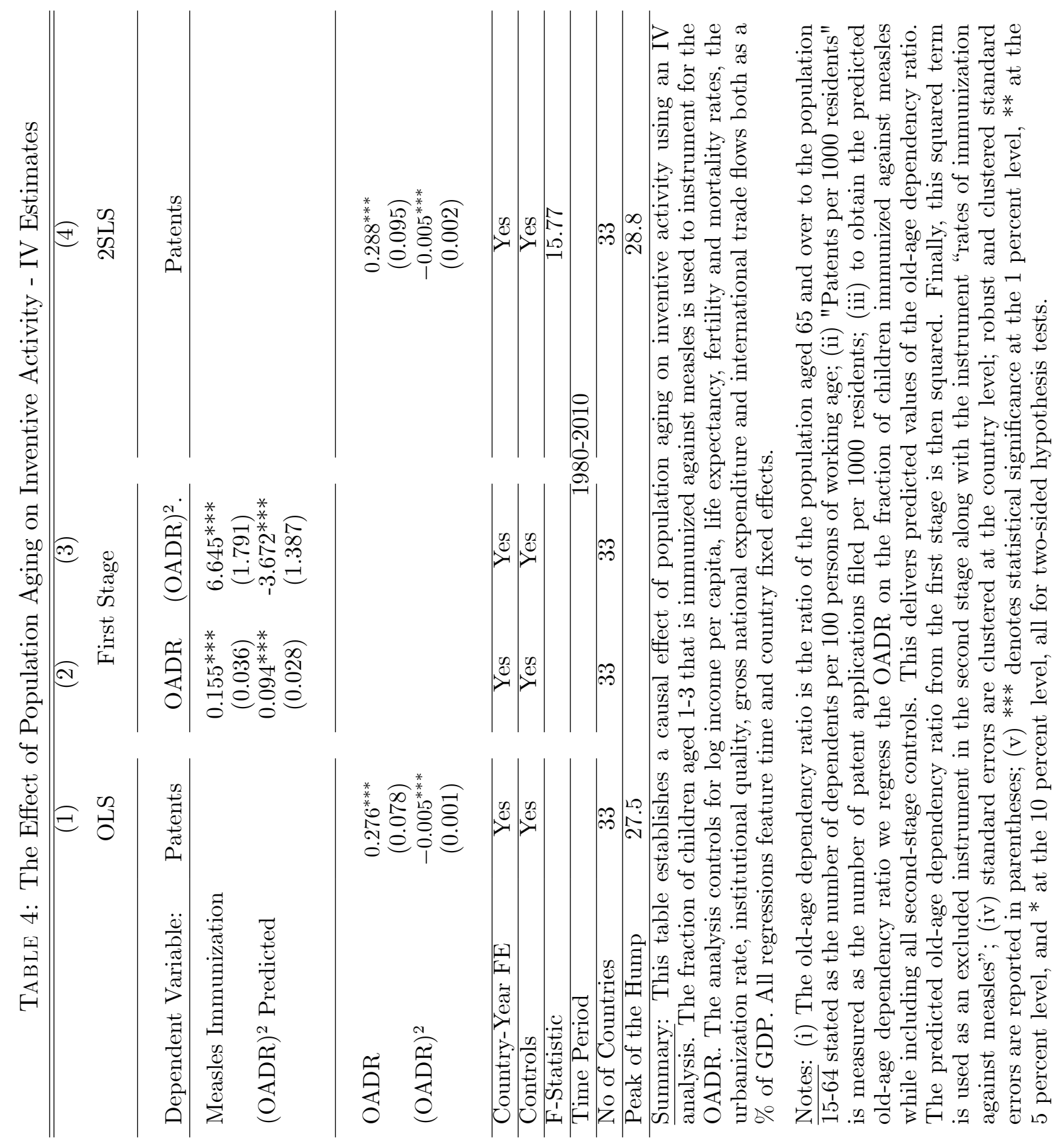


Robustness 


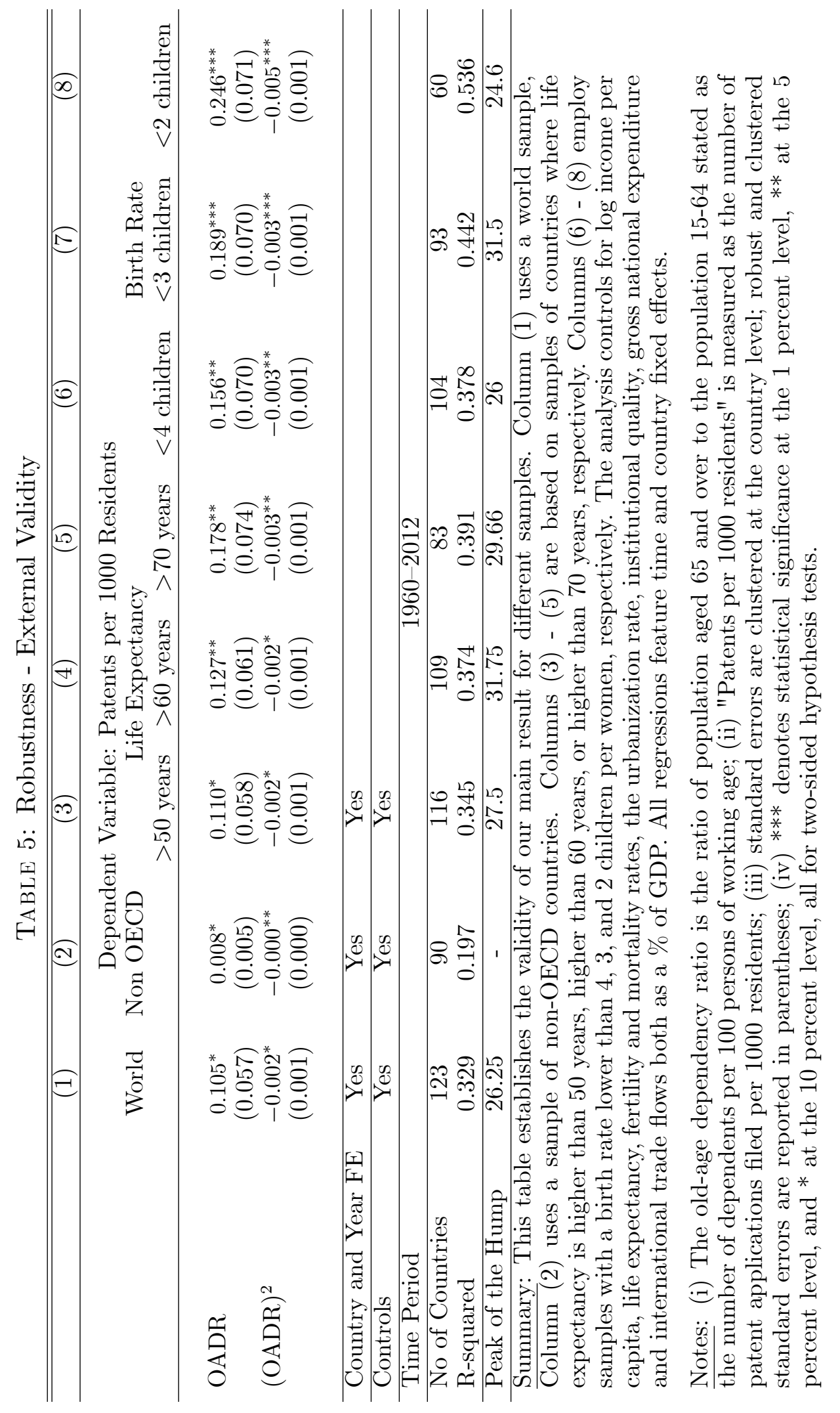




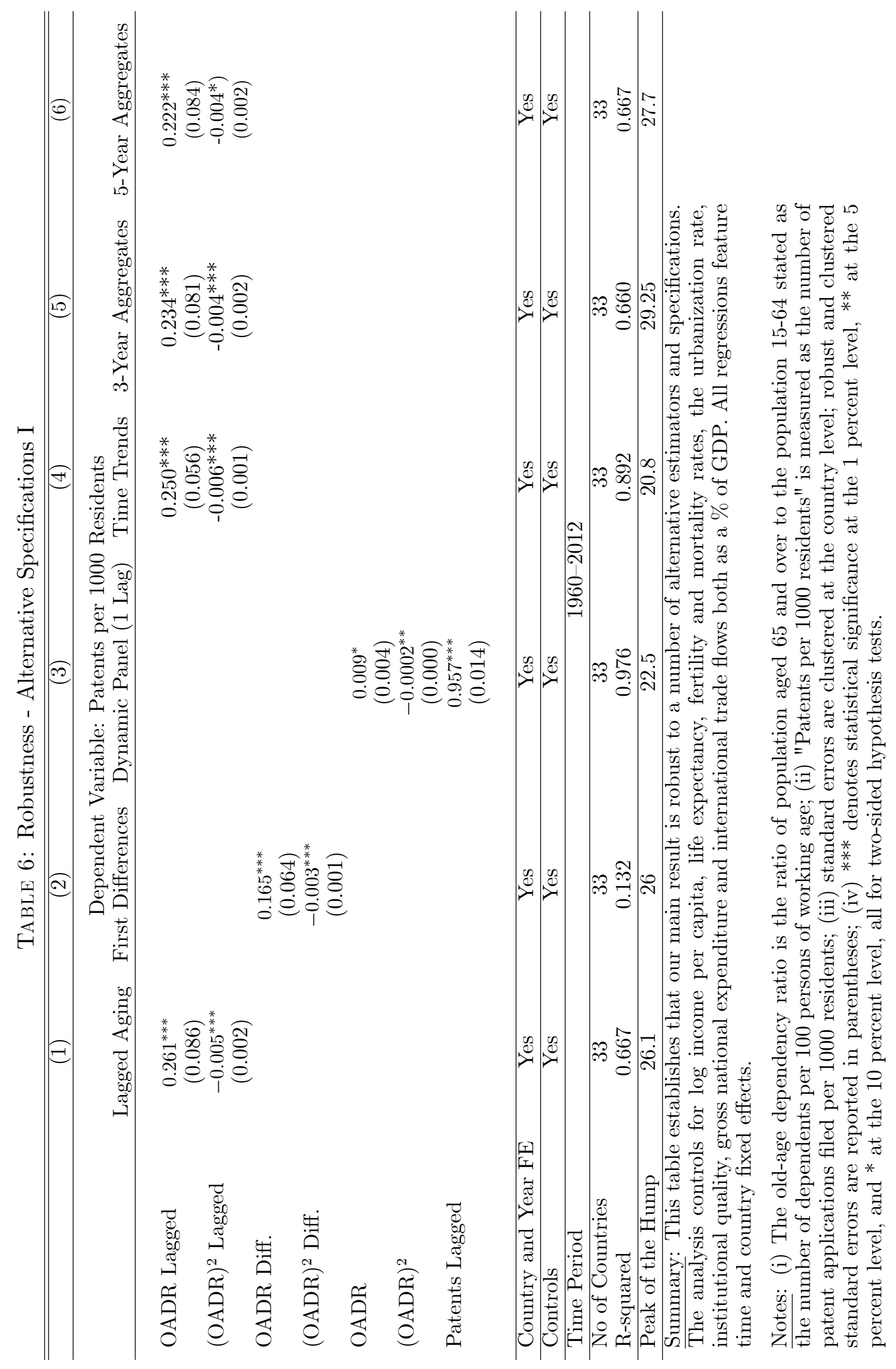


TABle 7: Robustness - Alternative Specifications II

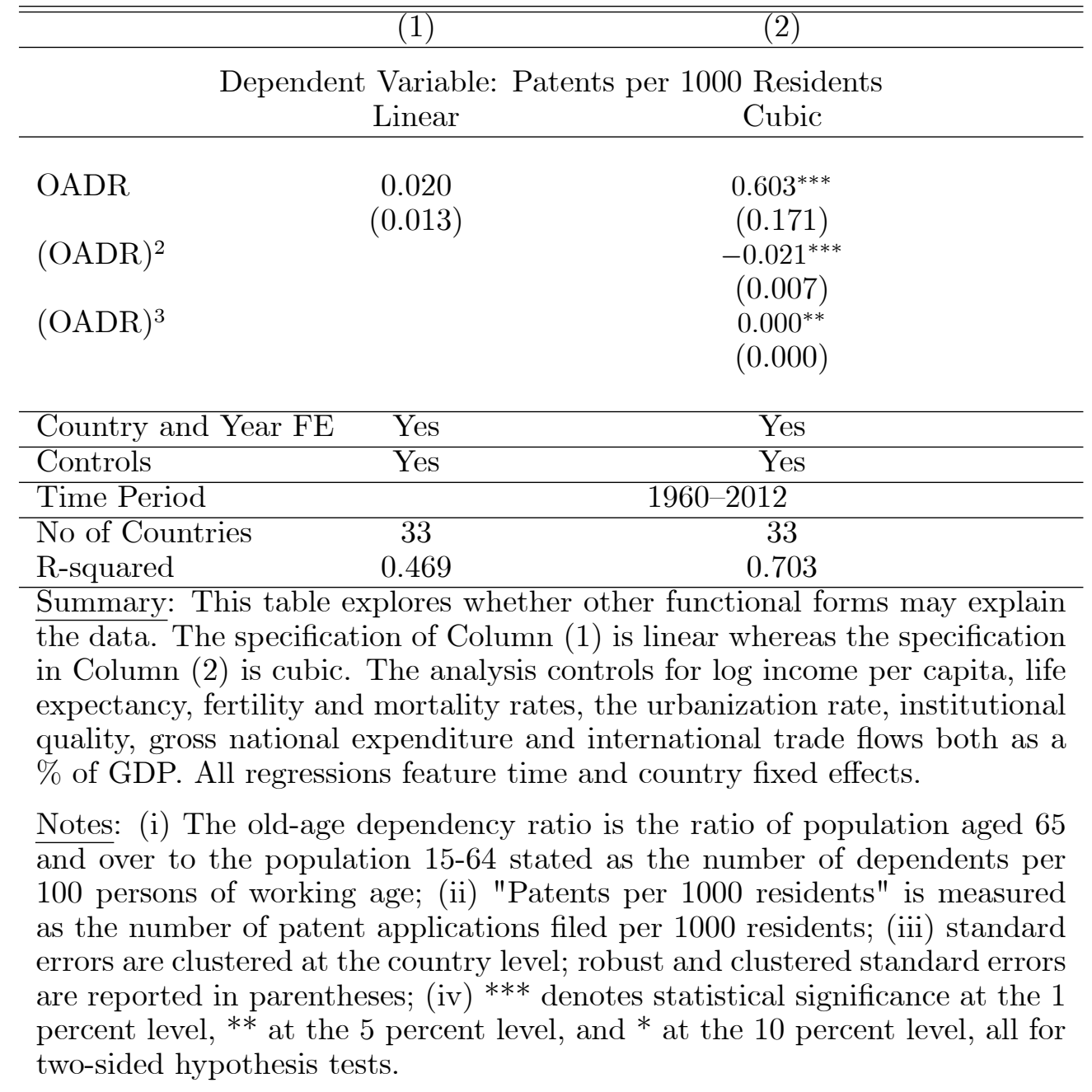




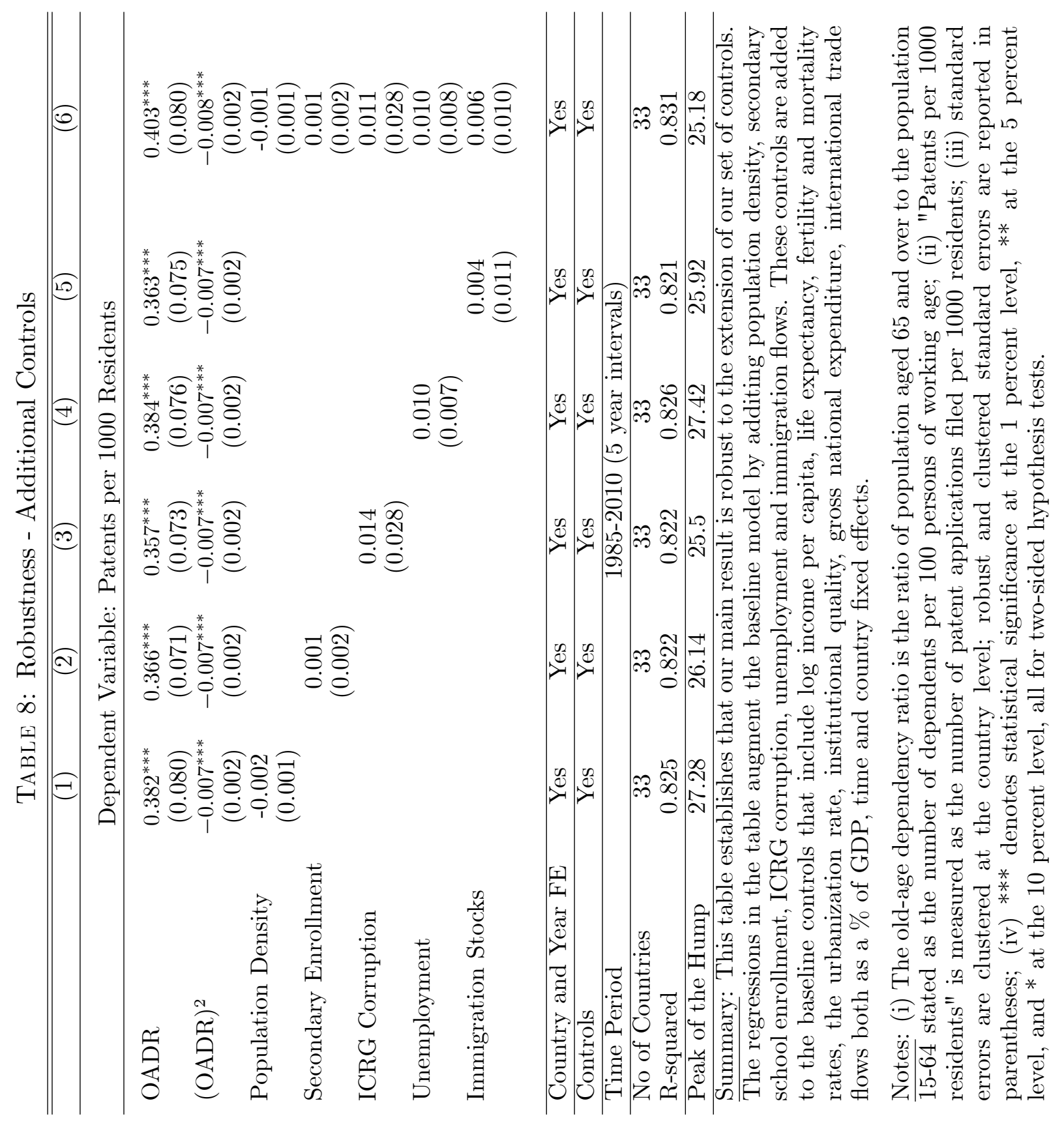


Discussion 


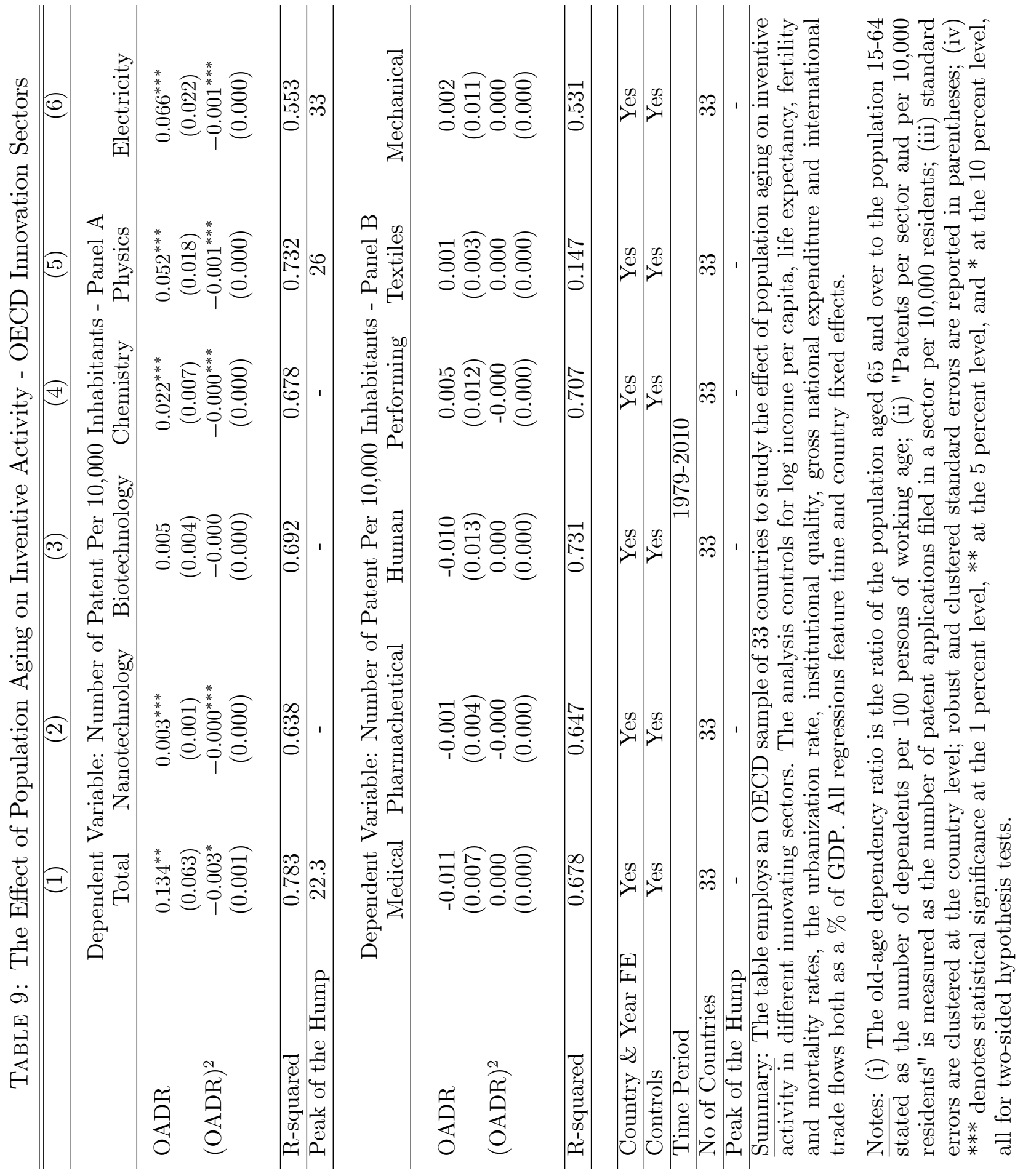


Table 10: The Effect of Population Aging on Inventive Activity - Demographic Structure, Pension Scheme and Retirement Age

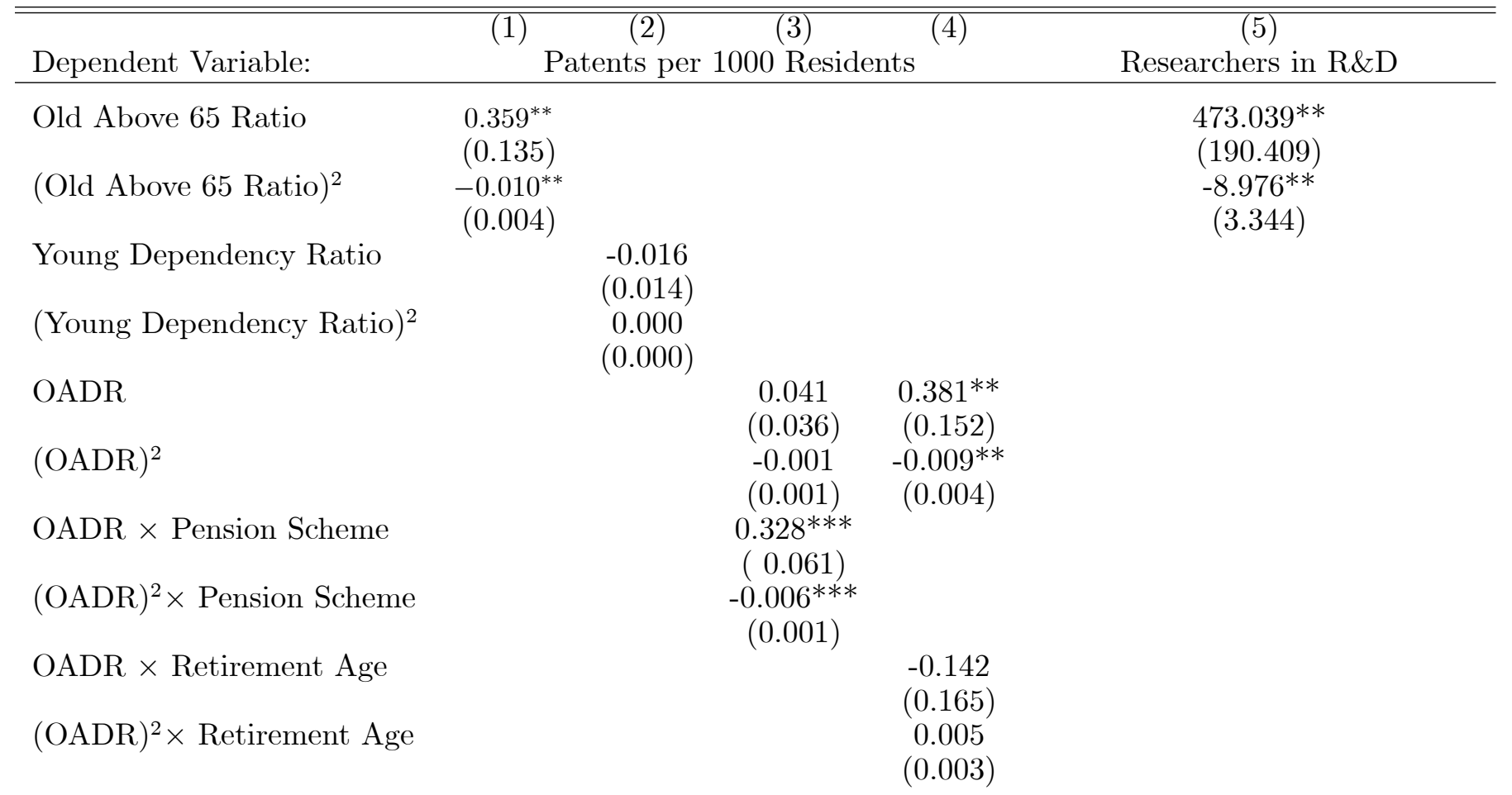

\begin{tabular}{|c|c|c|c|c|}
\hline Country \& Year FE & Yes & & & \\
\hline Time Period & \multirow{2}{*}{\multicolumn{3}{|c|}{$\frac{1960-2012}{33}$}} & $1997-2010$ \\
\hline No of Countries & & & & 32 \\
\hline R-squared & 0.653 & 0.345 & 0.693 & 0.691 \\
\hline Peak of the Hump & 17.9 & 27.3 & 21.16 & 26,36 \\
\hline
\end{tabular}

Summary: The table discusses several issues of interest related to our main result of a hump-shaped relationship between populaton aging and inventive activity. Column (1) employs the fraction of the old to the total population as the explanatory variable. The explanatory variable in Column (2) is the young dependency ratio. Column (3) interacts the OADR with the type of retirement system. Column (4) interacts the OADR with a threshold level for the retirement age. Column (5) employs as a proxy for inventive activity the number of researchers employed in R\&D. The analysis controls for log income per capita, life expectancy, fertility and mortality rates, the urbanization rate, institutional quality, gross national expenditure and international trade flows both as a \% of GDP. All regressions feature time and country fixed effects.

Notes: (i) The old above 65 ratio is measured as the number of people above the age of 65 as a fraction

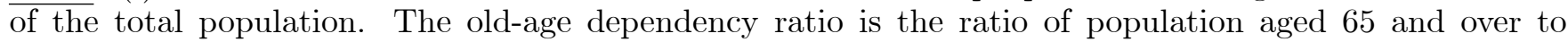
the population 15-64 stated as the number of dependents per 100 persons of working age. The youth dependency ratio is the ratio of individuals less than 16 to the total working age population (aged 15-64); (ii) "Patents per 1000 residents" is measured as the number of patent applications filed per 1000 residents; (iii) Retirement System is a dummy variable that takes on the value of 1 if the pension system in the country is PAYG and 0 otherwise; (iv) Retirement Age is a dummy variable that takes on the value of 1 if retirement age is above 63 and 0 otherwise; (v) standard errors are clustered at the country level; robust and clustered standard errors are reported in parentheses; (vi) *** denotes statistical significance at the 1 percent level, ${ }^{* *}$ at the 5 percent level, and ${ }^{*}$ at the 10 percent level, all for two-sided hypothesis tests. 


\section{References}

Bloom, D. and Sousa-Poza, A. (2013). Ageing and Productivity: Introduction, IZA Discussion Papers, No. 7205 .

Börsch-Supan, A. H. (2012). Policy Mixes in the Current European Pension Reform Process, DICE Report 10(4): 9.

Choi, I. (2001). Unit Root Tests for Panel Data, Journal of International Money and Finance 20(2): 249-272.

Feyrer, J. (2007). Demographics and Productivity, The Review of Economics and Statistics 89(1): 100-109.

Gehringer, A. and Prettner, K. (2014). Longevity and Technological Change, University of Göttingen, Center for European Governance and Economic Development Research, Discussion Papers No. 213.

Gonzalez-Eiras, M. and Niepelt, D. (2012). Ageing, Government Budgets, Retirement, and Growth, European Economic Review 56(1): 97-115.

Griffin, D. E. (2002). Measles Virus, In Wiley Encyclopedia of Molecular Medicine, John Wiley and Sons, Inc.

Irmen, A. (2013). Capital-and Labor-Saving Technical Change in an Aging Economy, CREA Discussion Paper Series 13-27 (International Economic Review, forthcoming) .

Irmen, A. and Litina, A. (2016). Population Aging and Culture: Do Old Societies Think Old Ideas?, mimeo, Center for Research in Economic Analysis (CREA), University of Luxembourg .

Jones, B. (2010). Age and Great Invention, The Review of Economics and Statistics 92(1): 114.

Jones, B., Reedy, E. and Weinberg, B. (2014). Age and Scientific Genius, NBER Working Paper, No. 19866 .

Judson, R. A. and Owen, A. L. (1999). Estimating Dynamic Panel Data Models: A Guide for Macroeconomists, Economics Letters 65(1): 9-15.

Kogel, T. (2005). Youth Dependency and Total Factor Productivity, Journal of Development Economics 76(1): 147-173. 
Kuehnel, J. (2011). Population Aging, the Composition of Government Spending, and Endogenous Economic Growth in Politico-Economic Equilibrium, in: Essays on the Theory of Productive Government Activity and Economic Growth, Chapter 4, PhD Dissertation, University of Heidelberg .

Nickell, S. J. (1981). Biases in Dynamic Models with Fixed Effects, Econometrica 49(6): 141726.

Packalen, M. and Bhattacharya, J. (2015). Age and the Trying Out of New Ideas, NBER Working Paper, No. 20920 .

Pesaran, M. (2004). General Diagnostic Tests for Cross Section Dependence in Panels, IZA Discussion Papers, No. 1240 .

Poterba, J. (2014). Retirement Security in an Aging Population, The American Economic Review 104(5): 1-30.

Prettner, K. (2013). Population aging and endogenous economic growth, Journal of Population Economics 26: 811-834.

Rechel, B., Doyle, Y., Grundy, E. and McKee, M. (2009). How Can Health Systems Respond to Population Ageing?, World Health Organisation, Policy Brief 10. .

Sauvy, A. (1948). Social and Economic Consequences of the Ageing of Western European Populations, Population Studies 2(1): 115-124.

Weil, D. (1997). The Economics of Population Aging, In Handbook of Population and Family Economics, Elsevier 1: 967-1014.

Wooldridge, J. M. (2010). Econometric Analysis of Cross Section and Panel Data, MIT press, Cambridge, Massachusetts. London, England. 


\section{Appendix: Variable Definitions and Sources}

\section{A. World Bank Indicators and Aggregate Data}

Patent Applications. Patent applications are worldwide patent applications filed through the Patent Cooperation Treaty procedure or with a national patent office for exclusive rights for an invention-a product or process that provides a new way of doing something or offers a new technical solution to a problem. A patent provides protection for the invention to the owner of the patent for a limited period, generally 20 years. "Patents per 1000 residents" is measured as the number of patent applications filed per 1000 residents. The source of the data is the World Development Indicators and the World Intellectual Property Organization (WIPO).

Researchers in Research and Development. Researchers in R\&D are professionals engaged in the conception or creation of new knowledge, products, processes, methods, or systems and in the management of the projects concerned. Postgraduate PhD students (ISCED97 level 6) engaged in $R \& D$ are included. The source of the data is the World Development Indicators.

Old Age Dependency Ratio (OADR). The old-age dependency ratio is the ratio of the population aged 65 and over to the population 15-64 stated as the number of dependents per 100 persons of working age. The source of the data is the World Development Indicators.

Fraction of Old above 65. The old above 65 ratio is measured as the number of people above the age of 65 as a fraction of the total population. The quadratic term is the squared term of the fraction of old. The source of the data is the World Development Indicators.

Youth Dependency Ratio. The youth dependency ratio is the ratio of individuals less than 16 to the total working age population (aged 15-64). The source of the data is the World Development Indicators.

GDP per Capita. GDP at purchaser's prices is the sum of gross value added by all resident producers in the economy plus any product taxes and minus any subsidies not included in the value of the products. It is calculated without making deductions for depreciation of fabricated assets or for depletion and degradation of natural resources. Data are in constant 2005 U.S. dollars. Dollar figures for GDP are converted from domestic currencies using 2000 official exchange rates. The source of the data is the World Development Indicators.

Mortality Rate. Adult mortality rate is the probability of dying between the ages of 15 and 60 -that is, the probability of a 15-year-old dying before reaching age 60, if subject to current age-specific mortality rates between those ages. The reported values is the mean mortality rate for men and women. The source of the data is the World Development Indicators.

Life Expectancy. Life expectancy at birth indicates the number of years a newborn infant would live if prevailing patterns of mortality at the time of its birth were to stay the same throughout its life. The source of the data is the World Development Indicators. 
Fertility Rates. Total fertility rate represents the number of children that would be born to a woman if she were to live to the end of her childbearing years and bear children in accordance with current age-specific fertility rates. The source of the data is the World Development Indicators.

Urbanization Rate. Urban population refers to people living in urban areas as defined by national statistical offices. It is calculated using World Bank population estimates and urban ratios from the United Nations World Urbanization Prospects.

Institutional Quality. The source of the data is the POLITY IV dataset and measures the level of democracy for all independent states. The variable takes values from -10 (dictatorship) to 10 (democracy).

Gross National Expenditure. Gross national expenditure (formerly domestic absorption) is the sum of household final consumption expenditure (formerly private consumption), general government final consumption expenditure (formerly general government consumption), and gross capital formation (formerly gross domestic investment). Data are expressed as a \% of GDP. The source of the data is the World Development Indicators.

Trade Flows. The source of the data is the WDI and it is the sum of exports and imports of goods and services measured as a share of gross domestic product.

Measles Immunization. Child immunization against measles is the fraction of children aged 1223 months who received a vaccination before their 12th month. A child is considered adequately immunized against measles after receiving one dose of vaccine. The source of the data is the World Development Indicators.

Retirement System. Using several OECD sources we construct a dummy variable that takes the value of 1 if the pension system is a Pay-As-You-Go (PAYG or unfunded) system and 0 in any other case (fully funded, partially funded, book reserved or any other combination). The data are constructed using the type of pension system as of the year 2005. The definitions for each funding scheme, as derived by the 2005 OECD report on the classification and glossary of private pensions (http://www.oecd.org/finance/private-pensions/38356329.pdf, accessed on July, 21st, 2015), are the following :

Unfunded pension plans: plans that are financed directly from contributions from the plan sponsor or provider and/or the plan participant. Unfunded pension plans are said to be paid on a current disbursement method (also known as the pay-as-you-go, PAYG, method). Unfunded plans may still have associated reserves to cover immediate expenses or smooth contributions within given time periods.

Funded (fully or partially) pension plans: occupational or personal pension plans that accumulate dedicated assets to cover the plan's liabilities. These assets are assigned by law or contract to the pension plan. Their use is restricted to the payment of pension plan benefits. 
Book reserved pension plans: sums entered in the balance sheet of the plan sponsor as reserves or provisions for occupational pension plan benefits. Some assets may be held in separate accounts for the purpose of financing benefits, but are not legally or contractually pension plan assets.

Retirement Age. Our variable on the retirement age is constructed using several OECD sources and takes the value of 0 if retirement age is below 63 and 1 otherwise (http://www.oecd.org/pensions/publicpensions/OECDPensionsAtAGlance2013.pdf, , accessed on July, 21st, 2015).

Population Density. Population density is a measure of population per unit area. The source of the data is the World Development Indicators.

School Enrolment. School enrolment ratio is the total enrollment in secondary education, regardless of age, expressed as a percentage of the population of official secondary education age. This variable can exceed $100 \%$ due to the inclusion of over-aged and under-aged students because of early or late school entrance and grade repetition. The source of the data is the World Development Indicators.

ICRG Corruption. A measure of corruption constructed by the PRS group. It takes values between - and 6 with 6 denoting the most corrupt country.

Unemployment. Unemployment refers to the share of the labor force that is without work but available for and seeking employment. Definitions of labor force and unemployment differ by country. The source of the data is the World Development Indicators.

Immigration Stocks. It measures the total migrant stocks residing in each OECD country. The source of the data is the World Development Indicators and they are available for every 5 year intervals. The source of the data is the World Development Indicators.

\section{B. OECD Data}

OECD Patent Applications. Patent applications are worldwide patent applications filed through the European Patent Office (EPO). The data are available from 1978 onwards. The measure is the total count of patents in each of the following sectors: Nanotechnology, Biotechnology, Chemistry, Physics, Electricity, Medical, Pharmaceutical, Human Necessities, Performing Operations, Textiles, Mechanical Engineering. The data are available from the OECD statistics. They are measured in per 10,000 residents units. A detailed description of each sector can be found at OECD 2008 Compendium of Patent Statistics (http://www.oecd.org/sti/inno/37569377.pdf, accessed on July, 21st, 2015) and at WIPO homepage (http://web2.wipo.int/ipcpub/\#refresh=page, accessed on July, 21st, 2015). 